\title{
VARIA
}

\section{LA LEYENDA DE «MESTRE» RIQUART Y DE RICCARDO QUARTARARO}

Extraña estrella y, sobre todo, venturosa, diría yo, la del oscuro mestre Ricart, uno de tantos pintores que trabajaban en la Valencia de la segunda mitad del siglo xv, elevado a los honores de la crónica en virtud de su presunta identificación con el célebre Riccardo Quartararo (1443-1507), el más excelente de los pintores palermitanos de su época. Todavía hoy, una buena parte de la crítica cree que Quartararo llegó a Valencia en 1472, en el séquito del cardenal Rodrigo Borja, futuro Alejandro VI, junto con el napolitano Francesco Pagano y el emiliano Paolo de San Leocadio. Puesto que, como intentaré explicar a continuación, con mi prolongado y voluntario silencio sobre el tema, me considero en parte responsable de la difusión de lo que creo un equívoco, me parece llegado el momento de relatar cómo tuvo origen la hipótesis - para muchos estudiosos convertida ya en certeza - de que Riccardo Quartararo era uno de los pintores de Rodrigo de Borja, con la esperanza de interrumpir la larga cadena de sugestivas suposiciones que, a la luz de una rigurosa lectura de las fuentes documentales, aparecen del todo infundadas.

Fue Raffaello Delogu ${ }^{1}$-haciendo suya una hipótesis que le había comunicado oralmente Ferdinando Bologna - quien propuso la identificación de Riccardo Quartararo con mestre Riquart, nombre que aparece en los documentos de la catedral de Valencia, en los que se hallan mencionados también Francesco Pagano y Paolo de San Leocadio. Esta hipótesis fue acogida con entusiasmo y sin reservas por Andrée de Bosque, autora de un libro, editado en 1965, sobre los artistas italianos en España ${ }^{2}$.

Madame de Bosque, como afectuosamente la llamábamos los amigos, era una amable aristócrata belga que, licenciada en jurisprudencia, había ejercido en su juventud en París la profesión de abogado internacionalista, antes de dedicarse al periodismo, participando como tal, en los años treinta, en un tan atrevido como peligroso raid París-Pekín en un minúsculo aeroplano, raid que desgraciadamente, por un fallo del motor, se concluyó con un aterrizaje de emergencia en una zona desierta entre el Pakistán y la India, y madame de Bosque, socorrida por los arrieros de las caravanas, se vio obligada a proseguir el viaje hasta la India a lomo de camello. Así acabó su carrera periodística. Dotada de una fogosa imaginación, se divirtió componiendo escenarios para el cine francés y, en edad ya avanzada, aún escribió el guión de un film sobre Juan de Austria, el héroe de Lepanto, que, por mi mediación, propuso a Luchino

\footnotetext{
1 Delogu, R., La Galleria Nazionale della Sicilia, Roma 1962, p. 38.

${ }^{2}$ De Bosque, A., Les artistes italiens en Espagne du XIV siècle aux rois catholiques, Paris 1965; trad. italiana, Gli artisti italiani in Spagna dal XIV secolo ai re cattolici, Milano 1968.
} 
Visconti, pero éste desventuradamente murió antes de que pudiera llevarse a término el proyecto. Después de una larga pausa debida a los acontecimientos bélicos, la emprendedora y ya anciana señora, poseída por una gran pasión por las obras de arte y contando con cuantiosos medios que le permitían tanto adquirirlas como recorrer el mundo en su búsqueda, se dedicó a la historia del arte, frecuentando los cursos de la École du Louvre. Enamorada de España que había recorrido a lo largo y a lo ancho, decidió, por sugerencia de André Chastel, centrarse en el estudio de las obras de los artistas italianos que habían trabajado en la península ibérica. Éste era el tema de mis investigaciones en el marco del curso de especialización dirigido en Roma por Mario Salmi. Inevitablemente, por tanto, acabamos por encontrarnos, en 1962, en Barcelona mientras encargábamos el mismo material fotográfico en el Archivo Mas.

Yo estaba a punto de publicar mi ensayo sobre Paolo da San Leocadio ${ }^{3}$ y madame de Bosque, con aire de misterio, me comunicó que estaba en posesión de importantes novedades sobre los pintores de Rodrigo de Borja, corroboradas por documentos de la catedral de Valencia, que habría hecho públicas en un libro de inminente aparición, sin acceder obviamente a anticipármelas. Quedé sin saber qué hacer, e incluso mortificada. Tenía conciencia de haber estudiado a fondo los documentos transcritos por el canónigo Sanchis Sivera ${ }^{4}$. ¿Qué podía habérseme escapado? Por cautela ante las revelaciones anunciadas por madame de Bosque, quería renunciar a la publicación de mi artículo, pero mi Maestro, Mario Salmi, me disuadió de hacerlo, afirmando que mi investigación había sido llevada con rigor y honestidad, y que si otros estudiosos hubiesen aportado a continuación nuevos datos originales al argumento, yo habría encontrado la manera de reexaminarlo con serena objetividad, modificando mi pensamiento, si lo hubiese considerado oportuno. Me atuve al sabio consejo del Maestro y esperé con impaciente curiosidad la publicación del libro de Andrée de Bosque que, entre tanto, a pesar de nuestras opiniones completamente divergentes en historia del arte, se había convertido para mí en una querida, gran amiga. No era fácil substraerse a su encanto extraordinario que, unido a un gran señorío, cautivaba la simpatía de cuantos la encontraban. Sin embargo su vívida inteligencia y su indomable curiosidad no podían suplir la falta de rigor científico que se aprende sólo a lo largo de muchos años de aprendizaje, si se tiene la fortuna de estar guiados por un severo e iluminado Maestro. Por desgracia Andrée de Bosque no estaba familiarizada con los archivos, ni mucho menos con la lengua valenciana del siglo xv, y de esto me di cuenta con gran consternación cuando recibí su libro, donde el nombre de Riccardo Quartararo aparecía asociado al de Francesco Pagano en la didascalia al pie de la foto del fresco de la Natividad, conservado en la sala capitular de la catedral de Valencia ${ }^{5}$. La colaboración entre los dos pintores que la autora daba como un hecho, estaba en neta contradicción con cuanto se leía en uno de los documentos transcritos por Sanchis Sivera ${ }^{6}$. Me pregunté si la trascripción publicada por el canónigo era exacta y decidí ir a comprobarlo en persona. Me fui pues a Valencia para examinar personalmente el libre tercer dela pintura de la capella mayor, en el archivo de la catedral y hacer fotografiar el folio 34 que me interesaba. De esta manera pude presentar la foto del texto original a muchos estudiosos valencianos y catalanes. La respuesta fue unánime: las tan esperadas «novedades» sobre los pintores del cardenal Borja eran fruto de una precipitada, y por tanto errónea, lectura de aquellos documentos que contienen, entre las áridas líneas de un libro de cuentas, los acontecimientos de la catedral de Valencia a partir del $10^{\circ}$ de mayo de 1472. He aquí, brevemente lo que sucedió en aquel tiempo. Según una antigua tradición, en la conmemoración de Pentecostés se hacía descender de la bóveda de la capilla mayor una

\footnotetext{
${ }^{3}$ Condorelli, A., Paolo de San Leocadio, en «Commentari» XIV (1963), pp. 134-150; 246-253.

${ }^{4}$ Sanchís Sivera, J., La Catedral de Valencia, Valencia 1909.

5 De Bosque, A., op. cit., pp. 215-226.

6 Sanchís Sivera, J., op. cit., p. 1409, n. 2.
} 


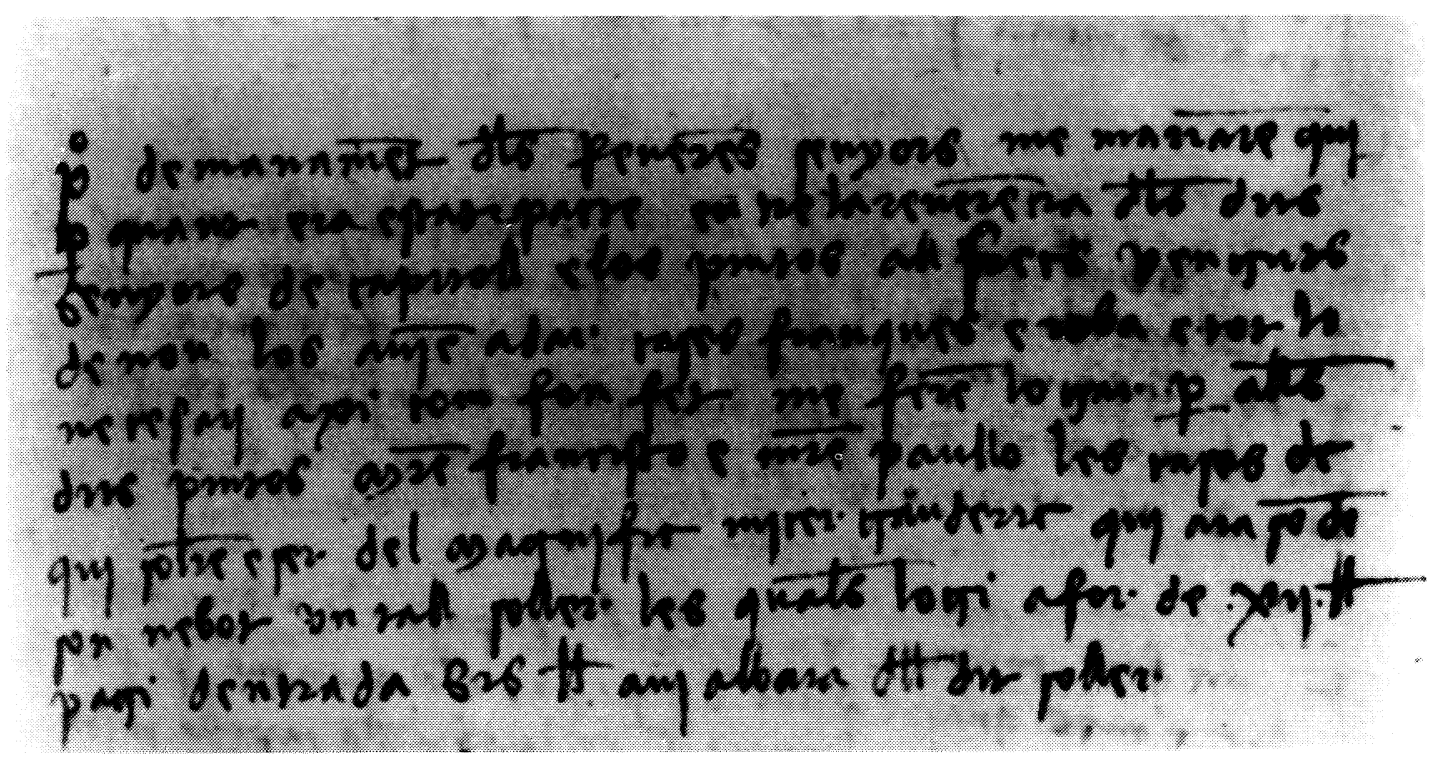

Fig. 1. Archivo de la Catedral de Valencia, Libre tercer de la pintura, fol. 34, par. 2.

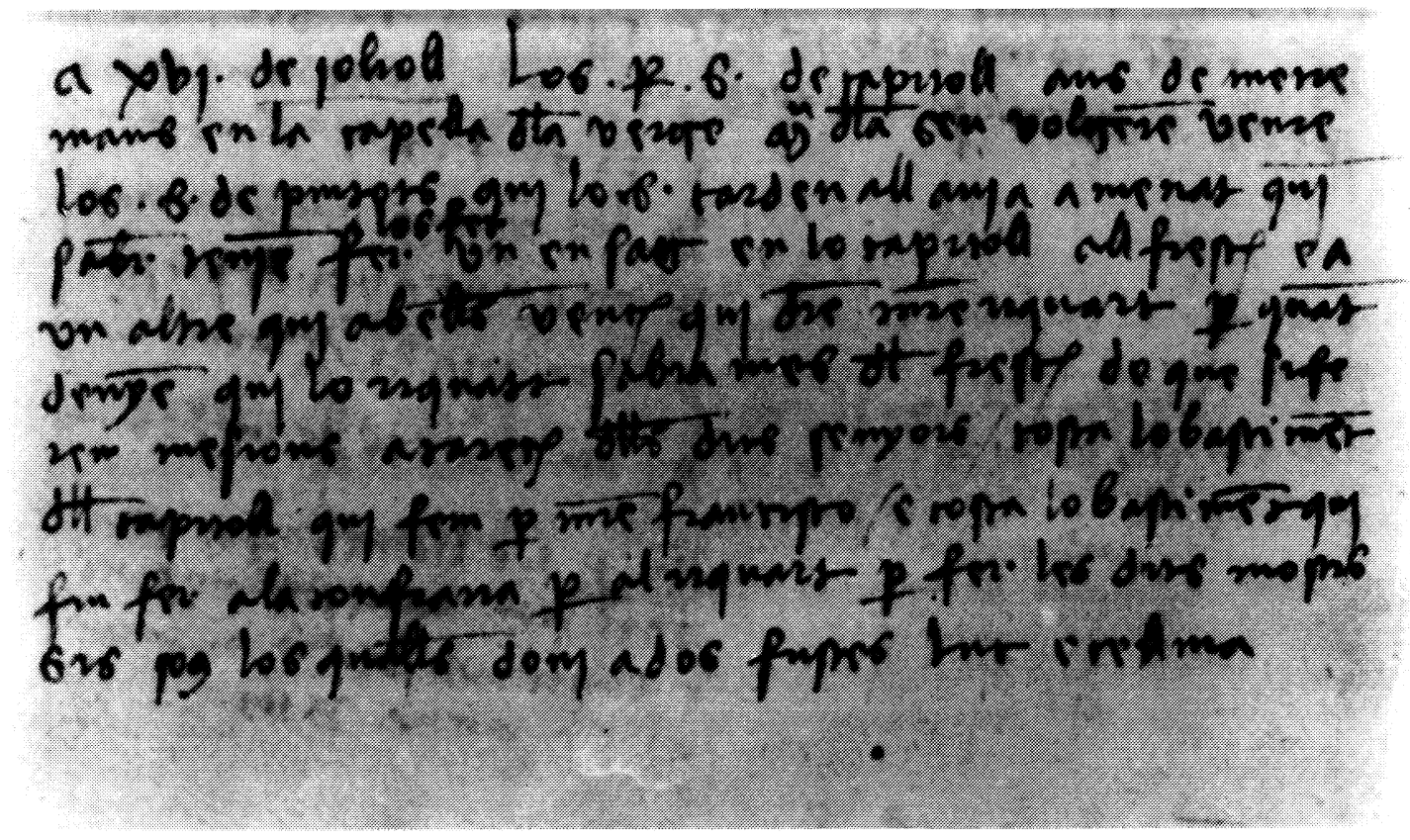

Fig. 2. Archivo de la Catedral de Valencia, Libre tercer de la pintura, fol. 34, par. 3.

paloma de plata, la palometa, repleta de copos de algodón embebidos en aceite y encendidos, que, al columpiarse, esparcía pequeñas ascuas, para imitar la bajada del Espíritu Santo. El efecto debía ser altamente sugestivo, pero también igualmente peligroso. Sucedió así que, el 21 de mayo de 1469, día de Pentecostés, durante la ceremonia, las ascuas provocaron un violento incendio que destruyó el gran retablo de plata y todos los frescos de la capilla mayor de la catedral. Desde entonces, el rito de la palometa fue definitivamente abolido ${ }^{7}$. Para los canónigos del capítulo, sin embargo, restablecer la decoración al fresco constituía una empresa extremamente difícil. 
Es sabido que en el siglo xv, en España, la pintura mural era ejecutada sólo por maestros italianos, segons cascuna practica e usança de Italia e del dit art de pintura al fresch ${ }^{8}$. En Valencia, en el campo de la pintura, los encargos tenían por objeto casi exclusivamente obras sobre tabla, desde los grandes y complejos retablos para las iglesias, hasta los pequeños cuadros de devoción que las casas privadas ponían sobre sus reclinatorios. Por tanto, los artistas valencianos, habilísimos en pintar al óleo a la manera flamenca, no tenían ningún interés en esforzarse por aprender una técnica que de poco les habría servido. Conscientes de este hecho, los canónigos de la catedral hicieron venir sin dilación de Salamanca, donde residía, a Nicola Fiorentino, que había pintado al fresco un Juicio Universal en la cuenca absidal de la catedral vieja de Salamanca, sobre el imponente retablo ideado y pintado por su hermano mayor Dello Delli, con la ayuda de colaboradores ${ }^{9}$.

Fueron encargadas a Nicola las pinturas murales de la capilla mayor de la catedral de Valencia, con la obligación, sin embargo, de ejecutar una prueba sobre la pared de la sala capitular, según el inexorable procedimiento exigido por los canónigos, por el cual los pintores, antes de comenzar el trabajo que les encomendaban en la catedral, tenían que demostrar su propia capacidad. Nicola Fiorentino pintó una Adoración de los Magos que se conserva aún en la sala capitular, aunque en parte destruida y mal repintada. Desgraciadamente, poco tiempo después, Nicola enfermó y murió, probablemente en noviembre de 1470. Para los canónigos, encontrar un pintor tan hábil en el arte del fresco como lo había sido Nicola Fiorentino, constituía pues otro grave problema.

El 15 de julio de 1471 se llevó a cabo una tentativa, confiando el trabajo a dos pintores valencianos, Pedro Rexat y Antonio Traycat o Canytar, quienes dieron prueba de tal ineptitud y mal gusto, que fueron despedidos e incluso procesados a sólo dos meses de haber comenzado la obra ${ }^{10}$. Entretanto, a los reverendos padres del capítulo se les presentó una gran oportunidad para hacer venir de Italia pintores de consolidada experiencia en el arte del fresco. El 23 de diciembre de 1471 Rodrigo de Borja fue nombrado, junto con otros cinco cardenales, legatus a latere, con el cometido, como dicen las actas consistoriales, de hacer apelo a todo el orbe cristiano para obtener fondos que permitiesen combatir el «nefandissimo» turco. A cada cardenal se le asignó el país que debía visitar. Obviamente el destino de Rodrigo fue España, y al cardenal, que era también arzobispo de Valencia, debió dirigirse el capítulo de la catedral para resolver el insoluble problema de los frescos. El 5 de mayo de 1472, el cardenal se embarcó en Ostia con rumbo a Valencia, a donde llegó el 18 de junio del mismo año, acogido con todos los honores y con la magnificencia reservada a los príncipes reinantes ${ }^{11}$. Que Francesco Pagano de Nápoles y Paolo de San Leocadio «de Areggio» formasen parte del numeroso séquito cardenalicio, lo encontramos escrito en un documento del 16 de julio de 1472, donde se especifica que los dos pintores fueron conducidos a la catedral de Valencia por el cardenal. A pesar de esto, no pudieron eludir la voluntad de los reverendos canónigos del capítulo, quienes, según la costumbre, antes de asignar los trabajos de la capilla mayor, dedicada a la Virgen, exigían una prueba de su habilidad, obligando a mostrar un espécimen de pintura al fresco realizado en la sala capitular. En el mismo documento, trascrito y publicado por Sanchis Sivera ${ }^{12}$,

\footnotetext{
7 Sanchís Sivera, J., Llibre de Antiquitats. Manuscrito existente en el Archivo de la Catedral de Valencia, Valencia 1926, pp. $19-20$.

8 Sanchís Sivera, J., La Catedral de Valencia, p. 152.

${ }^{9}$ Condorelli, A., Precisazioni su Dello Delli e Nicola Fiorentino, en «Commentari» XIX (1968) pp. 197-211; Ead. I contributi di Mario Salmi su Dello Delli ed il retablo della Cattedrale Vecchia di Salamanca, en Mario Salmi storico dell'arte e umanista, «Atti della giornata di studio. Roma, Palazzo Corsini, 30 novembre 1990», Spoleto 1991, pp. 141-150.

${ }^{10}$ Archivo de la Catedral de Valencia, Segon libre de la pintura, fol 20 yss.; Sanchis Sivera J., La Catedral de Valencia, p. 148

11 Sanchís Sivera, J., Llibre de Antiquitats, pp. 1-3.

12 Sanchís Sivera, J., La Catedral de Valencia, p. 149, n. 2.
} 
se lee que también a otro pintor que ab ells venc (que había venido con ellos), llamado mestre Riquart, le fue consentido hacer un fresco de prueba, a pesar de que los canónigos «decían» que Riquart era más versado que los dos italianos en el arte del fresco. Se montaron, por tanto, dos andamios: uno en la sala del capítulo para mestre Francesco y el otro en la sala de la cofradía para Riquart. Un fragmento del ensayo de Francesco Pagano y de Paolo de San Leocadio, que representa la Natividad, se conserva aún en la sala capitular de la catedral de Valencia. Por el contrario, no existe la menor traza del de mestre Riquart, ya nunca más citado en los documentos de la catedral. El encargo de pintar los frescos de la capilla mayor fue, de hecho, confiado a Francesco Pagano y a Paolo de San Leocadio y el contrato se estipuló solemnemente el 28 de julio de 1472, en presencia del cardenal.

Aun queriendo creer a toda costa que bajo el nombre de mestre Riquart se ocultaba Riccardo Quartararo, es evidente que éste no era un «pintor de los Borja», como se le ha definido, sino un antagonista de los dos italianos protegidos del cardenal. Riquart se había presentado con ellos en la catedral para someterse a la prueba, con el único fin de ganar el concurso. No puede excluirse que fuese italiano, pero habría podido ser español, francés, alemán o flamenco, ya que en los florecientes talleres valencianos pululaban los artistas extranjeros, quienes, en perfecta armonía, colaboraban en la ejecución de las obras de arte.

Es evidente que mestre Riquart no podía de ninguna manera haber pintado con Francesco Pagano, en la sala capitular, el fresco de la Natividad, dado que exclusivamente para él se había levantado otro andamio en la cofradía. Por tanto, la afirmación de madame de Bosque que este fresco representa una obra auténtica de mestre Riquart, alias Riccardo Quartararo, resulta privada de cualquier fundamento.

«Es cierto que el sueño de la razón produce monstruos» fue el irónico comentario de José Gudiol, entonces director del Instituto Amatller de Arte Hispánico de Barcelona, al pedirme que publicase los documentos del archivo de la catedral de Valencia, añadiendo que, si no lo hacía, el error divulgado por madame de Bosque habría, con el tiempo, echado raíces profundas, difíciles de extirpar. Sin saber qué hacer, en Madrid, pedí consejo a Diego Angulo Iñiguez, quien, fijando en mí sus ojos azules y sonriendo dulcemente, murmuró: «pero ¿cómo se puede dar un disgusto así a una señora tan amable?» Eran exactamente las palabras que yo quería oírme decir y decidí callar. Por lo demás, pensé, los documentos son de dominio público; cualquiera que estuviese interesado en el asunto, yendo a las fuentes, habría podido notar el error y rectificarlo. Me limité, por tanto, a exponer mi pensamiento sobre el caso sólo a poquísimos amigos, cuando me lo pedían expresamente. Muy pronto me di cuenta, sin embargo, de que la sombra de la duda, fundamento de cualquier investigación, no florece en todos los estudiosos y, en Italia especialmente, siguiendo el sendero trazado por madame de Bosque, el fresco de la Natividad que se halla en la sala capitular de Valencia, continuó a ser considerado obra de Riccardo Quartararo y de Francesco Pagano ${ }^{13}$.

Pasando los años, de tanto en tanto me encontraba entre las manos la foto del famoso folio del archivo de la catedral de Valencia. Algo en la trascripción hecha por Sanchis Sivera no me había nunca convencido del todo, en particular la afirmación de que los canónigos dien qui lo riquart sabia mas del fresc, es decir «decian» que Riquart estaba más impuesto en el arte del fresco que Francesco Pagano y Paolo de San Leocadio. Enseñé el documento a Juan Nadal y Cañellas, catedrático de Bizantinología en el Pontificio Instituto Oriental de Roma, quien, confrontando el texto original con la traducción de Sanchis Sivera, me hizo notar que éste se ha-

${ }^{13}$ La única estudiosa que se disoció del coro de los aquiescencentes fue María Andaloro, quien, con perspicacia, señaló que la identificación de Quartararo con mestre Ricart abría la vía a un nuevo fílón de estudios que estaba obteniendo mucho consenso, pero que tenía el peligro de crear confusión en el problema de Quartararo (Andaloro, M., Riccardo Quartararo dalla Sicilia a Napoli, «Anuario dell'Istituto di Storia dell'Arte, Università di Roma» 1974/75, 1976/77, pp. 81-124: 121 . 
bía equivocado al transcribir una palabra clave que cambiaba todo el sentido del documento: los canónigos no dien, sino denyen, es decir «negaban» que Ricart fuese más experto en fresco que los otros dos pintores. Para mayor seguridad, el texto fue examinado también por Anscari Mundó i Marcet, catedrático de paleografía de la Universidad Autónoma de Barcelona, quien confirmó plenamente la lectura de Juan Nadal, lo que, por tanto, nos obliga a una nueva interpretación del documento. Los reverendos padres del capítulo conocían, pues, muy bien a mestre Riquart, tan bien como para saber que no era capaz de pintar al fresco. Fuese valenciano o extranjero, debía residir desde hacía algún tiempo en Valencia y, por tanto, no podía haber llegado un mes antes en el séquito de Rodrigo de Borja con mestre Francesco e mestre Paulo ... los pintos al fresc venguts de nou, los pintores llegados recientemente, a los cuales los reverendos señores del capítulo concedieron inmediatamente, gratis, casa, vestidos y todo lo que les fuese necesario ${ }^{14}$.

Es lícito suponer, además, que las poderosas corporaciones de pintores valencianos, a pesar de la dolorosa humillación sufrida el año anterior, hubiesen intentado enfrentarse, tratándose de un encargo tan importante, a los dos pintores italianos y, sabiamente, los canónigos, para evitar penosas polémicas, habían consentido en que un representante suyo, mestre Riquart, hiciese un ensayo de prueba, pese a que ellos «negaban» que pudiese ser más experto que los otros dos en materia de fresco. De hecho, fracasado en su intento, Riquart retorna a la oscuridad de la cual había salido.

Recientemente, la correcta lectura de los documentos que, por una interpretación poco escrupulosa, sufragaban la presunta estancia en Valencia, en 1472, de Riccardo Quartararo, ha permitido a Teresa Pugliatti colocar bajo una luz nueva el problema de la formación del pintor palermitano, reexaminando con gran rigor científico su recorrido artístico en un capítulo, claro y exhaustivo, de su volumen sobre la pintura del Cinquecento en Sicilia Occidental ${ }^{15}$.

No se puede, por tanto, ya aceptar la hipótesis de que un artista de la valía de Riccardo Quartararo pueda ser todavía identificado con el desventurado mestre Riquart, tenido en tan poca consideración por los reverendos señores del capítulo de la catedral de Valencia.

\section{APÉNDICE DOCUMENTAL}

Archivo de la Catedral de Valencia, Libre tercer de la pintura, fol. 34, par. 2:

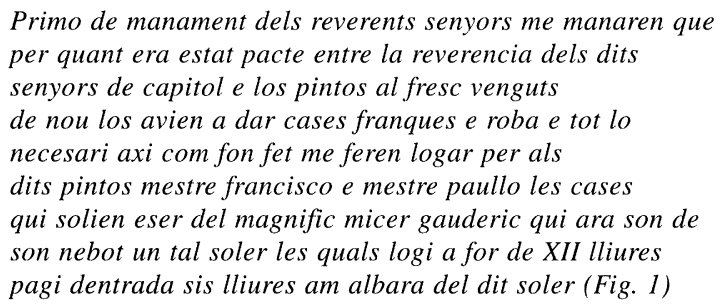

Primero, por mandato de los reverendos señores: me ordenaron que por cuanto había sido pactado entre la reverencia de dichos señores del cabildo y los pintores al fresco recién llegados se les tenía que dar casa franca, ropa y todo lo necesario, y así se hizo. Me hicieron alquilar para los citados pintores, maestro Francisco y maestro Paulo, las casas que habían sido del magnifico micer Gauderich, que ahora son de su sobrino, un tal Soler, las cuales alquilé a razón de XII libras; pagué de entrada seis libras, con albarán del citado Soler.

\footnotetext{
${ }^{14}$ Sanchís Sivera, J., La Catedral de Valencia, p. 149, n. 1.

15 Pugliatti, T., Pittura del Cinquecento in Sicilia, 2, La Sicilia Occidentale, 1484-1557, Napoli 1998; Ead., Riccardo Quartararo: una pesonalità da rivedere, in Arte d'Occidente. Tema e metodi. Studi in onore di Angela Maria Romanini, Roma 1999, pp. 1063-1070.
} 
Ibid., par. 3:

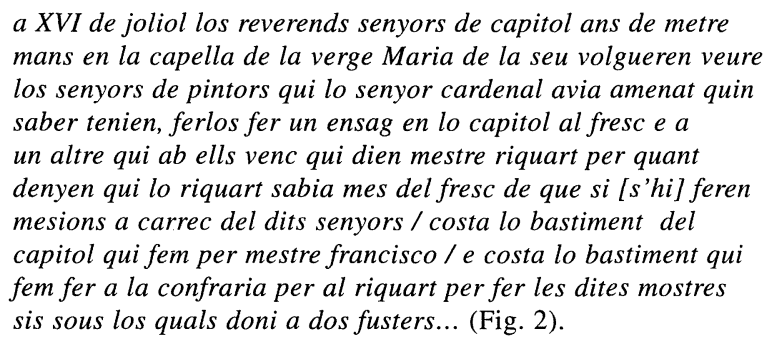

El XVI de julio, los reverendos señores del cabildo, antes de meter mano a la capilla de la Virgen de la Catedral, quisieron conocer de los señores pintores que el Sr. Cardenal había traído qué saber tenían, [y] hacerles hacer un ensayo de la pintura al fresco en la sala capitular, y a otro que con ellos vino, al cual llamaban mestre Riquart, aunque negaban que el Riquart supiese más de fresco, por lo cual se hicieron gastos a cargo de dichos señores. Costó el andamio de la sala capitular que hicimos para mestre Francisco y costó el andamio que hicimos hacer en la cofradía para mestre Riquart, para hacer las dichas muestras, seis sueldos, los cuales entregué a dos carpinteros [...]

Adele Condorelli

\section{DOS NUEVAS OBRAS DE FRANCISCO GALLARDO}

La localización de dos lienzos firmados por Francisco Gallardo, uno en Sevilla y otro en Cádiz, amplía las escasas noticias que se conocen sobre la vida y obra de este autor ${ }^{1}$. El cuadro de Cádiz, de propiedad particular, es un trampantojo del tipo conocido como «rincón de taller» y sus dimensiones son $83 \times 62 \mathrm{cms}$. En él destaca una estampa, sobre la que se posa una mosca, clavada al habitual fondo de tablas, y en cuya zona inferior se puede leer: «En Cádiz, año de $1720 \ldots$ Franco. Julo. Gallado F.». Bajo la estampa hay una cinta, sujeta con puntas y atravesada en uno de los extremos por un punzón, que sirve de soporte a una carta plegada en la cual aparece escrito: «Sr. Dn. Franco X...». La obra conservada en Sevilla, también de propiedad particular, mide $157 \times 108 \mathrm{cms}$. y representa a santo Tomás de Aquino. Está firmada: «Franco. Gallardo fecit anno...», aunque en este caso se desconoce la fecha, perdida seguramente en el proceso de reentelado que redujo levemente las dimensiones del lienzo. El momento representado corresponde a una de las visiones místicas del santo, quien, interrumpiendo sus escritos, se arrodilla ante un crucifijo que le dirige las siguientes palabras: «BENE SCRIPSISTI DE ME THOMA». En la zona superior se abre una gloria donde revolotean varios ángeles niños y sobre el pavimento se disponen dos mitras y un capelo, que simbolizan las dignidades eclesiásticas rechazadas ${ }^{2}$.

Estos dos trabajos se suman al reducido catálogo de Francisco Gallardo, compuesto hasta ahora por cuatro trampantojos firmados y fechados en 1764, a los que se puede añadir la atribución de otros cuatro lienzos del mismo género pertenecientes a la colección André Hipola

\footnotetext{
1 Francisco Gallardo fue dado a conocer en la exposición de bodegones y floreros organizada por la Sociedad Española de Amigos del Arte en 1935. Véase Cavestany, J.: Bodegones y floreros en la pintura española, Madrid, 1936-1940, p. 96.

${ }^{2}$ La biografía de Santo Tomás de Aquino recoge varias experiencias místicas de este tipo, en las que Cristo elogia sus escritos. Sobre su repercusión en las creaciones artísticas se ha señalado la existencia de un fresco con este mismo tema en el claustro de Santa María sopra Minerva de Roma. Véase Mâle, E.: El Barroco. El arte religioso del siglo xvII, Madrid, 1985, pp. 409-410.
} 